\title{
The Relationship between Health Outcomes and Household Socio-Economics Characteristics
}

\author{
Steven Henry Dunga \\ North West University, School of Economic Sciences, Vanderbijlpark, South Africa \\ Steve.dunga@nwu.ac.za
}

\begin{abstract}
The economic circumstance of a household is in most cases linked to the varied situations a household may find itself income is to a greater extent linked to the housing and food that a household is exposed to. Income among other socio-economic factors may also affect the demand structure of the household in terms of what the household may consider necessary or not. The level of household demand for health services and its preventive level may also be associated with other household characteristics especially those associated with the head of the household. This paper analysed the relationship between the morbidity rate in a household and the household characteristics and the characteristics of the head of household. The paper uses data collected in the South African general household survey published in 2017 conducted by Statistics South Africa. Based on a sample of 21601 households, the study employs a multinomial logistic model with the level of morbidity rate categorised into a high level, mild, and low. The results of the empirical analysis show that Household size, the gender of head of household, housing insecurity status age of head of household and income were significant determinants of morbidity rate at the household level. The contribution of the paper is therefore a proposal for preventive mitigation as opposed to treatment which tends to be more expensive on government. The fact that housing insecurity is a competing need with health demand calls for better alignment in terms of government, provision of health services in South Africa. This paper is motivated by the initiative of the introduction of a national health Insurance (NHI) is South Africa.
\end{abstract}

Keywords: Socio-economic, morbidity rate; household; determinants; health outcomes

\section{Introduction}

Healthy living has been a priority of at both micro and macro levels because of the consequences of its neglect if fatal. The importance of health in an economic sense is ubiquitous in the literature (Drimie \& Casale, 2009; Helsing, Moyses, \& Comstock, 1981; Hutchinson et al., 2004; Paul Schultz, 2002). It can also be acknowledged that health deterioration can be observed before it becomes serious and hence the importance of preventive behaviour is advocated before looking for a cure, as the old adage says prevention is better than cure. Therefore, the demand for healthcare is superseded by the demand for healthy living. However, this paper hypothesises that there are household conditions that make it impossible for households to prevent themselves from practicing proper preventive behaviour. Morbidity rate or frequency in terms of getting sick is a term measurement that helps to determine the health level of a household or an individual it can also be used on a macro level in an aggregated sense for a specific illness. At household level one can use the hospital visitation or the rate at which sickness is experienced in the household as a measure of household health outcome. The interest with health and hence morbidity rate is that it impacts on both the productivity of the labour force in a macro sense and also impact on the health expenditure especially where the majority of the population is not covered by private health insurance.

The discussion is South Africa has of late concentrated on the public health sector and the fact that it is in a state of crumbling. There are a number of reasons that can be attributed to the failing state of the public health sector. The inequality in income distribution is arguably one of the main reasons, we discuss this in detail in a paper on 'determinants of demand for private healthcare in South Africa' the transmission mechanism as we would put it in economics being that, the country has afforded the private health sector to discriminate the less fortunate by making health insurance so highly priced that it is out of reach by a majority. The inequality comes in in the sense that there still enough people that can afford the expensive health covers that the providers do not see the need to capture more customers by reducing the price. There are also cartel tendencies in the sector which have removed the competition aspect and hence operating with a monopolist output. This paper however looks at how household social economic characteristics determine their health outcomes focusing on the rate of illness or hospital visitation. The interest in that is that it helps to focus resources on the point of service that is most effective and cost-efficient. Having a better 
understanding of what determines the demand for healthcare can therefore go a long way in dealing with inefficiencies in health spending (Benzeval et al., 2014; Dahl \& Lochner, 2012).

\section{Literature Review on Health Outcome and Household Characteristics}

This section presents theoretical and empirical premise for the independent variables and how they are associated with health outcomes, hereafter measured as morbidity rate. The paper discusses income and its relationship with an individual or household health (Hutchinson et al., 2004; Who, 2003; Woolf et al., 2015), education and health, housing and health (Archer, Murie, Turkington, \& Watson, 2016; Bonnefoy, 2007; Krieger \& Higgins, 2002; Rauh, Landrigan, \& Claudio, 2008; World Health Organization, 2007) and food security and health (FAO, 2013; Labadarios et al., 2011; UN, 2016; Weiser et al., 2015). The variables discussed in this literature section are the ones used as dependent variables, including other variables like age and household size. Morbidity can be a good proxy of the illness rate or health of a population or a sample.

Income and Health Outcomes: The link between income and health can be considered to be simultaneous, or multidimensional. The common argument for reducing poverty for example has been that it will improve a number of household circumstances including their health position (Benzeval et al., 2014). The report by the Rowntree Foundation identifies key theories that explain how money influences health. They pointed out that there is a materialistic, Psychosocial and behavioural explanations to the link between income and health (Benzeval et al., 2014; Braveman, Egerter, \& Barclay, 2011). The materialist argument is that money buys health-promoting goods and services and enables an individual to engage in social life in ways that enable them to be healthy. The psychosocial argument is that stress of having not having enough money may lead to worry and may affect one's health. And the behaviour argument points the fact that people living in disadvantaged circumstances may be more likely to have unhealthy behaviour, and being in poor health may affect education and employment opportunities in ways that affect subsequent health (Benzeval et al., 2014; Woolf et al., 2015). There are therefore strong arguments that improving people access to income may go a long way in dealing with their demand for health and the tress on the public health sector, in the sense that there will be low demand on health or that they may be able to afford private healthcare. Woolf et al. (2015) found that the hypothesis that people with higher incomes and wealth are likely to be healthier than those with lower income than theirs was true based on the US data.

Education and Health Outcomes: The link of education to health is largely associated with the income argument. Most educated people have a higher chance of earning an income and hence have access to better healthcare and can afford services that give them better health outcomes (Zimmerman \& Woolf, 2014) However there are studies that have shown that the relationship between education and health goes beyond the income argument (Cutler \& Lleras- Muney, 2016; Feinstein, Sabates, Anderson, Sorhaindo, \& Hammond, 2006; Groot \& van den Brink, 2006). The literature shows that the relationship between education and health is more complicated than is assumed in the anecdotal discussions. Cutler and Lleras-Muney analysed data from the National Health Interview Survey (NHIS), which includes a large number of health outcomes and behaviours and one of their outcomes was the educated people are less likely to self-report a past diagnosis of an acute and chronic disease and also less likely to die from common diseases (Cutler \& Lleras- Muney, 2016). Besides the income mechanism, education can also be linked to health in the sense that education people are aware of the basic hygiene required to prevent them from catching common diseases.

Housing and Health Outcomes: Housing insecurity is a concept that has not received enough attention, although housing itself is understood as an important basic human need (Broton \& Goldrick-Rab, 2018; Rauh et al., 2008). The literature does not have a clear measure or scale to measure hosing insecurity at the household level (Mncayi \& Dunga, 2017). In a series of paper we have been developing a measure of housing insecurity using income, the material used for the construction and household size (Dunga \& Grobler, 2017b; Mncayi \& Dunga, 2017). The link between housing insecurity and health outcome however is ubiquitous in the literature (Archer et al., 2016; Bonnefoy, 2007; Rauh et al., 2008). The nature of housing that the household is accommodated in goes a long way in determining the health of the household. A housing secure household is one that is not congested, has proper structure and does not use more than $30 \%$ of the household income for its cost (Dunga \& Grobler, 2017a). A good house or a housing secure household stands 
a better chance of avoiding communicable diseases. There are a number of diseases that are related to exposure to poor housing. Housing without inside plumbing for example means that the household has to find ways to source water. The quality of water sources from outside the household could be unsafe to a larger extent. There are many other linkages can be derived from poor housing or housing insecurity to health.

Food Security and Morbidity Rate: There can be no other important determinant of health than the food one eats or the access and or availability of food. Food security at household level therefore has a bearing on the health of the members of the household especially children. There are a number of studies that have shown the link between food security and health (FAO, 2013; Institute, 2016; UN, 2016). Households may sometimes be faced with a situation where food and housing become competing needs due to the level of resources at their disposal. In such cases different households have different utility structures, with others preferring food to better housing and others preferring good housing to a better food (Dunga \& Grobler, 2017a). Utility theories postulate that individuals are not identical and hence choices of what given the highest satisfaction may differ from household to household. A household that is housing insecure because of spending a bigger percentage of the household income on housing maybe trading off food and health care and such trade-off has health consequences (Broton \& Goldrick-Rab, 2018; Dunga \& Grobler, 2017a; Rauh et al., 2008).

\section{Method and Data}

The paper uses data collected in the South African general household survey published in 2017 conducted by Statistics South Africa (STATSSA, 2017). The survey collected data from 21601 households across the nine provinces in the country. The sample was representative of the populations in the provinces. Table 1 shows the percentage contribution of each province to the sample.

Table 1: Sample by Province

\begin{tabular}{llll}
\hline Province & Frequency & Percentage & Cumulative frequency \\
\hline Western Cape & 2146 & 9.9 & 9.9 \\
Eastern Cape & 2824 & 13.1 & 23.0 \\
Northern Cape & 951 & 4.4 & 27.4 \\
Free State & 1350 & 6.2 & 33.7 \\
KwaZulu-Natal & 3536 & 16.4 & 50.0 \\
North West & 1499 & 6.9 & 57.0 \\
Gauteng & 5204 & 24.1 & 81.1 \\
Mpumalanga & 1724 & 8.0 & 89.0 \\
Limpopo & 2367 & 11.0 & 100.0 \\
Total & 21601 & 100.0 & \\
\hline Sourc: & & &
\end{tabular}

Source: Author Calculation from GHS (2018)

The study employs a multinomial logistic regression model since the dependent variable is a categorical variable with categories measured with levels of morbidity rate categorised into a high level, moderate and low. The morbidity rate was calculated based on the frequency of household visits to the hospital or doctor. The assumption also made under this measurement is that each sickness resulted in a visit to the hospital or general practitioner (GP) ceteris paribus. Table 2 presents frequencies for the three categories of the morbidity rate categorised variable

Table 2: Morbidity Rate Categorised

\begin{tabular}{lllll}
\hline & Frequency & Percent & Valid Percent & Cumulative Percent \\
\hline High rate & 17735 & 82.1 & 82.1 & 82.1 \\
Moderate & 2416 & 11.2 & 11.2 & 93.3 \\
Low rate & 1450 & 6.7 & 6.7 & 100.0 \\
Total & 21601 & 100.0 & 100.0 & \\
\hline
\end{tabular}

Source: Calculations from the data 
The frequency table 1 shows the three categories of the dependent variable. The higher percentage in the high rate category is most likely exaggerating the morbidity rate since there was no accurate measure of the health outcome and the proxy of using the visit to the hospital is not an accurate measure. The housing security was based on the proxy of the material used in the construction of the walls of the house. Since South Africa data is used in this study, the material used in the construction of a house in the south African context, gives enough indication as to whether the housing is in a formal setting or not and also the housing security potential.

Model Specification: The dependent variable being categorical with more than two categories, an appropriate model therefore would be a multinomial logistic regression model. The model is specified as follows;

$$
\begin{gathered}
\ln \frac{\operatorname{Pr}\left(Y_{i}=1\right)}{\operatorname{Pr}\left(Y_{i}=N\right)}=\boldsymbol{\beta}_{1} * \boldsymbol{X}_{\boldsymbol{i}} \ldots \\
\ln \frac{\operatorname{Pr}\left(Y_{i}=2\right)}{\operatorname{Pr}\left(Y_{i}=N\right)}=\boldsymbol{\beta}_{2} * \boldsymbol{X}_{\boldsymbol{i}} \ldots \\
\ln \frac{\operatorname{Pr}\left(Y_{i}=N-1\right)}{\operatorname{Pr}\left(Y_{i}=N\right)}=\boldsymbol{\beta}_{N-1} * \boldsymbol{X}_{\boldsymbol{i}} \ldots
\end{gathered}
$$

For a dependent variable with $\mathrm{N}$ categories, and hence $\mathrm{N}-1$ binary logistic models are estimated with the, with the $\mathrm{N}^{\text {th }}$ model being used as the reference model. This is built on the understanding that a multinomial logistic regression uses linear predictor function $f(N, i)$ to predict the probability that observation i has $\mathrm{N}$ outcomes with a form as follows

$$
f(N, i)=\beta_{0 . n}+\beta_{1, n} x_{1, i}+\beta_{2, n} x_{2, i}+\cdots+\beta_{M, n} x_{M, i} \ldots(4)
$$

Where $\beta_{M, n}$ is a regression coefficient corresponding to the $m$ th regressor and the $n$th outcome the regression coefficients and explanatory variables can therefore be grouped into vectors of size $M+1$, so that the predictor function is then written more compactly as equan ation as

$$
f(N, i)=\boldsymbol{\beta}_{, n} . \boldsymbol{X}_{, i} \ldots(5)
$$

And thus the representation used in equations 1 to 3 above where all the independent variables have been compacted in the vector. The three models to be estimated are the high morbidity rate and the moderate morbidity rate with the third category of low morbidity rate being the reference model. The results of the models are presented in tables 4 and 5 .

\section{Results and Discussion}

In the presentation of results and interpretation, a good understanding is achieved with a presentation of a step by step of the results starting with the descriptive statistics of the variables and then the regression results.

Descriptive Statistics: The data was comprised of 21601 households that were interviewed. Table 3 presents the distribution of the gender of the head of household as this is also an important variable in explaining the household characteristics that are associated with morbidity rate at the household level.

Table 3: Gender Distribution in the Sample

\begin{tabular}{llllll}
\hline \multicolumn{2}{l}{ Gender of Household Head } & Frequency & Percent & Valid Percent & Cumulative Percent \\
\hline Valid & Male & 12592 & 58.3 & 58.3 & 58.3 \\
& Female & 9009 & 41.7 & 41.7 & 100.0 \\
& Total & 21601 & 100.0 & 100.0 & \\
\hline
\end{tabular}

The results in table 3 show that there is a higher percentage (58.3\%) of households that are headed by a male head of household, compared to female-headed households which take up $41.7 \%$ of the sample, this however a fair distribution as there is no over-representation. 


\begin{tabular}{l} 
Journal of Economics and Behavioral Studies (ISSN: 2220-6140) \\
Vol. 10, No. 6A, pp. 89-96, 2018 \\
\hline \hline
\end{tabular}

Table 4: Results of the Likelihood Ratio Test

\section{Model Fitting Criteria Likelihood Ratio Tests}

-2 Log Likelihood of

Effect

Intercept

Household size

Age of household head

log income

Sex of household head

Wall condition

Reduced M
$20660.708^{a}$
21185.252
20985.573
20667.209
20889.738
20688.815

Chi-Square

.000

524.544

324.865

6.501

229.030

28.107

$\begin{array}{ll}\text { DF } & \text { Sig. } \\ 0 & . \\ 2 & .000 \\ 2 & .000 \\ 2 & .039 \\ 2 & .000 \\ 10 & .002\end{array}$

The chi-square statistic is the difference in -2 log-likelihoods between the final model and a reduced model. The reduced model is formed by omitting an effect from the final model. The null hypothesis is that all parameters of that effect are 0 .

a. This reduced model is equivalent to the final model because omitting the effect does not increase the degrees of freedom.

The results in table 4 show that the all variables entered in the regression make a significant contribution to the model and hence they all are included in the final model reported in table 5. All the variables in the likelihood ratio test have a p-value of less than 0.05 for the $5 \%$ significance level. Hence all the variables are significant at the $5 \%$ significance level.

Table 5: Results of the Multinomial Logistic Regression Model

\begin{tabular}{|c|c|c|c|c|c|c|c|}
\hline \multirow[t]{2}{*}{ Model } & \multicolumn{7}{|c|}{ Std. } \\
\hline & Regressors & B & Error & Wald & DF & Sig. & $\operatorname{Exp}(B)$ \\
\hline High & Intercept & .237 & .333 & .505 & 1 & .477 & \\
\hline morbidity & Household size & .334 & .020 & 286.537 & 1 & .000 & 1.396 \\
\hline \multirow[t]{10}{*}{ rate model } & Age of household head & .028 & .002 & 175.527 & 1 & .000 & 1.028 \\
\hline & Log income & .012 & .023 & .269 & 1 & .604 & 1.012 \\
\hline & Male head of household & -.828 & .069 & 144.668 & 1 & .000 & .437 \\
\hline & Female head of household & $0^{\mathrm{b}}$ & . & . & 0 & . & . \\
\hline & Housing insecure & .510 & .275 & 3.440 & 1 & .064 & 1.666 \\
\hline & Moderate housing insecurity & .343 & .261 & 1.723 & 1 & .189 & 1.409 \\
\hline & Mildly housing insecure & .551 & .256 & 4.630 & 1 & .031 & 1.735 \\
\hline & Mildly secure & .599 & .252 & 5.661 & 1 & .017 & 1.820 \\
\hline & Moderately secure & .788 & .261 & 9.115 & 1 & .003 & 2.199 \\
\hline & Housing secure & $0^{\mathrm{b}}$ & . & . & 0 & . & . \\
\hline Moderate & Intercept & -1.090 & .421 & 6.695 & 1 & .010 & \\
\hline morbidity & Household size & .165 & .022 & 53.975 & 1 & .000 & 1.179 \\
\hline \multirow[t]{10}{*}{ rate model } & Age of household head & .008 & .003 & 10.663 & 1 & .001 & 1.008 \\
\hline & Log income & .057 & .028 & 4.149 & 1 & .042 & 1.059 \\
\hline & Male head of household & -.369 & .081 & 21.008 & 1 & .000 & .691 \\
\hline & Female head of household & $0^{\mathrm{b}}$ & . & . & 0 & . & . \\
\hline & Housing insecure & .455 & .358 & 1.610 & 1 & .204 & 1.576 \\
\hline & Moderate housing insecurity & .511 & .341 & 2.251 & 1 & .134 & 1.668 \\
\hline & Mildly housing insecure & .707 & .335 & 4.456 & 1 & .035 & 2.028 \\
\hline & Mildly secure & .716 & .330 & 4.703 & 1 & .030 & 2.046 \\
\hline & Moderately secure & .769 & .340 & 5.119 & 1 & .024 & 2.158 \\
\hline & Housing secure & $0^{\mathrm{b}}$ & . & . & 0 & . & . \\
\hline Reference $n$ & del is the low morbidity rate $\mathrm{M}$ & & & & & & \\
\hline
\end{tabular}

The results in Table 5 compare the high rate morbidity model and the moderate rate morbidity model to the reference model is the low rate morbidity model. In the interpretation of the results, the emphasis is on the signs of the coefficients and the odds ratio presents in the last column of the table. Based on the results in 
table 5, household size is positively associated with a high morbidity rate. This could be due to congestion in the house where people are crowded in single rooms and hence becomes very easy to pass on to each other diseases especially those that can be passed on by mere contact. This also agrees with the literature that shows the relationship between housing security and health (Rauh et al., 2008). Also in the calculation of housing security, overcrowding in a house is an indication of housing insecurity. The moderate morbidity model also has similar results that show that the higher the number of people in a household the higher the probability of having a moderate morbidity rate than the probability of a low morbidity rate. The odds show that a unit change in the household size increases the odds of being in the high morbidity rate by 1.028 and also increases the odds of being in the moderate rate by 1.179. The age of the head of household has a positive coefficient for both models. In the high morbidity rate, the positive coefficient implies that the older the head of household the higher the morbidity rate in the household.

This is in agreement with a priori expectations, where older people are expected to fall sick more frequently than younger people due to the fact that as one gets old the body becomes weak and hence the immunity, the system is not as strong as that of younger people. In the economic sense, it may be due to the fact that they are not economically active anymore and hence may not have enough resources to afford them healthy foods and a healthy lifestyle. The same result is also found in the moderate rate morbidity rate model as both these models are compared to the low rate morbidity model. Income which was converted to logs has a negative coefficient, which means that people with higher incomes reported higher morbidity rate. This is not in agreement with the expectations as higher incomes were supposed to afford the household a good lifestyle and hence have a lower morbidity rate. However, based on the results of the model, it is not the case for both the high and the moderate morbidity rate models. The explanation could be that these people with higher income were fast to react to any simple illness by going to the doctor due to the fact that they had medical coverage and hence ended up reporting higher morbidity rate.

The other explanation could be that the disease that contributes highly in South Africa is flu and one's income can hardly protect them from flu as it is an airborne disease that attacks the rich and the poor equally. On gender of head of household, the male head of household which was defined as 1 in the coding of the categorical variable in the regression has a negative coefficient. This means that males are less likely to fall in the high morbidity rate category and also less likely to fall in the moderate morbidity rate than are likely to fall in the low morbidity category compared to females. The literature also suggests that females are more likely to fall sick than male due to their childbearing responsibilities which in many cases may also trigger other medical issues (Cameron, Song, Mnaheim, \& Dunlop, 2010; Fikree \& Pasha, 2004; HLEG, 2010). The results in tables 5 show that the odds of falling into a high morbidity rate category are 0.437 less for males than it is for females and for the moderate morbidity rate it is 0.691 less for males than it is for females. This means that females will have a higher chance of not of getting sick but also of reporting to the doctor as females are considered to be more responsive to any medical issues than are males. The other variable considered in the model was the housing insecurity which was entered as a categorical variable with 5 categories, with the housing secure being the reference category.

All the other 4 categories were compared to the housing secure category. For the first model, the probabilities of falling in the high morbidity rate category were considered for the 4 categories of housing insecurity in comparison to the housing secure and the low morbidity rate model. For the moderate morbidity rate a similar process was followed, still maintaining housing secure as the reference category, and low morbidity rate as the reference model. The results show that housing insecure households are more likely to fall in the high morbidity rate category compared to the housing secure. This is also the case for all the other categories of housing which moderate insecure, mild insecure, mild secure and moderate secure, all these compared to the housing secure category are more likely to fall in the high morbidity rate and the moderate morbidity categories. This is in agreement with a theory which points to the importance of housing in people's health outcomes. Thus housing plays an important role in determining the exposure of households to diseases especially cold-related diseases like flu which are common in South Africa. Thus poverty cannot be dealt with if households are not able to be involved in economic activities due to higher morbidity rate. 


\section{Conclusion}

The paper attempts to make a link between morbidity rate and household characteristics. It is emanating from the understanding that policies are put in place to deal with poverty which remains a big challenge for most sub-Saharan Africa countries including South Africa. It is argued therefore, that in order to deal with poverty all facets of the problem have to be considered, including housing and exposure to diseases that may reduce the availability of people to participate in economic activities. Linking morbidity rate to household characteristics helps to establish which variables are important in determining the morbidity rate at the household level and hence what needs to be done for households to deal with these deterrents to full economic participation. The results of the multinomial logistic model show that age, gender, household size and housing insecurity are some of the household's characteristics that are significant in explaining the morbidity rate at the household level. Age has a positive association with morbidity rate household size also has a positive association with morbidity rate. This means that older people need to be considered differently than younger people. The issue of household size can only be dealt with from an education point of view. Literature shows that higher levels of education among women lead to lower fertility levels.

Thus in order to make sure that household sizes are of manageable levels, the policies to deal with such can only be medium to long-term as education can easily be promoted among those that are in school and not those that are already out of school (Chisadza, 2015; Groot \& van den Brink, 2006). Housing security at the household level is also very important in determining the morbidity rate and hence the economic participation of the household. There are already policies in place in South Africa to improve the housing situation of a poor household. However, more needs to be done especially the development of a clear understanding of what entails housing security both in the country and internationally. There exist gaps in the literature as to the measure of housing security (Broton \& Goldrick-Rab, 2018; Dunga \& Grobler, 2017a; Nazli \& Malik, 2003). The paper recommends that a succinct scale be developed that can measure housing security at household level.

\section{References}

Archer, P., Murie, A., Turkington, R. \& Watson, C. (2016). Good Housing: Better health. The AcademicPractitioner Partnership, (July), 28.

Benzeval, M., Bond, L., Campbell, M., Egan, M., Lorenc, T., Petticrew, M. \& Popham, F. (2014). How does money influence health? JRF - Joseph Rowntree Foundation, (March), 70.

Bonnefoy, X. (2007). Inadequate housing and health: an overview. International Journal of Environment and Pollution, 30(3/4), 411.

Braveman, P., Egerter, S. \& Barclay, C. (2011). Income, Wealth and Health. Exploring the Social Determinants of Health, (April).

Broton, K. M. \& Goldrick-Rab, S. (2018). Going Without: An Exploration of Food and Housing Insecurity Among Undergraduates. Educational Research, 47(2).

Cameron, K., Song, J., Mnaheim, L. \& Dunlop, D. (2010). Gender Disparities in Health and Healthcare Use, Journal of Women's Health, 19(9).

Chisadza, C. (2015). Education and Fertility : Panel Evidence from sub-Saharan Africa. Working Paper, (May).

Cutler, D. \& Lleras- Muney, A. (2016). Policy brief, (May), 1-11.

Dahl, G. B. \& Lochner, L. (2012). The Impact of Family Income on Child Achievement: Evidence from the Earned Income Tax Credit. American Economic Review, 102(5), 1927-1956.

Drimie, S. \& Casale, M. (2009). Multiple stressors in Southern Africa: the link between HIV/AIDS, food insecurity, poverty and children's vulnerability now and in the future. AIDS Care, 21(1), 28-33.

Dunga, S. H. \& Grobler, W. (2017a). The nexus of food and housing insecurity in south. International journal of social sciences and humanity studies, 9(2), 95-108.

Dunga, S. H. \& Grobler, W. C. J. (2017b). The nexus of food and housing insecurity in south. International journal of social science and humanity studies, 9(2), 95-108.

FAO. (2013). Food security and Nutrition in the Southern and Eastern rim of the Mediterranean basin. (M. Smulders, M. Aw-Dahir, K. Dunn, \& R. Verduijn, Eds.).

Feinstein, L., Sabates, R., Anderson, T. M., Sorhaindo, A. \& Hammond, C. (2006). What are the effects of education on health? Proceedings of the Copenhagen Symposium, 26, 171-354. 
Fikree, F. F. \& Pasha, O. (2004). Role of gender in health disparity: the South Asian context. BMJ, 328(7443), 823-826.

Groot, W. \& van den Brink, H. M. (2006). What does education do to our health? Proceedings of the Copenhagen Symposium, 355-363.

Helsing, K., Moyses, S. \& Comstock, G. (1981). Factors associated with mortality after widowhood. Amer. J. Public Health, 71(8), 802-809.

HLEG. (2010). Gender and Health. High-Level Expert Group Report on Universal Health Coverage for India, 295-300.

Hutchinson, G., Simeon, D. T., Bain, B. C., Wyatt, G. E., Tucker, M. B. \& Lefranc, E. (2004). Social and Health Determinants of Well Being and Life Satisfaction in Jamaica. International Journal of Social Psychiatry, $50(1), 43-53$.

Institute, P. H. (2016). Food Security, Climate Change, and Health. Public Health Institute.

Krieger, J. \& Higgins, D. L. (2002). Housing and health: Time again for public health action. American Journal of Public Health, 92(5), 758-768.

Labadarios, D., Mchiza, Z. J. R., Steyn, N. P., Gericke, G., Maunder, E. M. W., Davids, Y. D. \& Parker, W. (2011). Food security in South Africa: a review of national surveys. Bulletin of the World Health Organization, 89(12), 891-899.

Mncayi, N. P. \& Dunga, S. H. (2017). Determinants of housing insecurity in a low income. International journal of economics and finance studies, 9(2), 117-133.

Nazli, H. \& Malik, S. J. (2003). Housing: Opportunity, Security, and Empowerment for the Poor. The Pakistan Development Review, 4, 893-906.

Paul Schultz, T. (2002). Why governments should invest more to educate girls. World Development, 30(2), 207-225.

Rauh, V. A., Landrigan, P. J. \& Claudio, L. (2008). Housing and health: Intersection of poverty and environmental exposures. Annals of the New York Academy of Sciences, 1136, 276-288.

UN. (2016). Food Security and Health Policy Brief by the Scientific Advisory Board of the UN SecretaryGeneral 28 December 2016, (December).

Weiser, S., Palar, K., Hatcher, A., Young, S., Frongillo, E. \& Laraia, B. (2015). Food Insecurity and Health: A Conceptual Framework. Food Insecurity and Public Health, (May), 23-50.

Who. (2003). DAC Guidelines and Reference Series: Poverty and Health.

Woolf, S. H., Simon, S. M., Aron, L., Zimmerman, E., Dubay, L. \& Luk, K. X. (2015). How Are Income and Wealth Linked to Health and Longevity? Urban Institute, (April), 1-22.

World Health Organization. (2007). Health in the Green Economy: Housing Sector, 1-6.

Zimmerman, E. \& Woolf, S. H. (2014). Understanding the Relationship Between Education and Health. IOM Roundtable on Population Health Improvement. 